\title{
CLINICAL OUTCOME OF USING A PIEZOELECTRIC DEVICE IN COMPARISON WITH CONVENTIONAL SURGICAL DRILLS IN SURGICAL MANAGEMENT OF THE TEMPOROMANDIBULAR JOINT ANKYLOSIS
}

\author{
Abdullah Hammuda* and Hamed Gad**
}

\begin{abstract}
Objectives: The aim of the current study was to evaluate clinical outcome of using piezoelectric device versus conventional surgical drills in surgery of TMJ ankylosis.

Patients and methods: A prospective study included 18 joints in 10 patients suffered from bony ankylosis of the TMJ who were surgically managed by gap arthroplasty at oral and Maxillofacial Surgery department Minia University Dental Hospital (MUDH) and Dar Al Shifa hospital of Egyptian Ministry of health. Postoperative outcomes of TMJ surgery were investigated and compared based on the following parameters: Postoperative mouth interincisal opening, intraoperative bleeding, length of the operation time, surgical site infection, surgical site swelling and postoperative pain.
\end{abstract}

Results: statistical analysis of reported data revealed that; in general there were statistical significant in increase in mouth opening for all patients. There were no significant changes between both groups in bleeding and surgical site infection score, however there were statistical significant increase in operative time and decrease the postoperative edema and pain score in piezoelectric device group.

Conclusion: piezoelectric bone removal for the release of ankylosis of the TMJ reduced postoperative complications its main disadvantage is the increase in operating time. The piezosurgery allows surgeons to achieve better outcomes compared to a conventional surgery and its possible alternative due to the clinical benefits demonstrated.

* Lecturer Oral and Maxillofacial Surgery, Faculty of Dentistry, Minia University

** Ass. Prof. Oral and Maxillofacial Surgery, Faculty of Dentistry, Minia University 


\section{INTRODUCTION}

Ankylosis in Temporomandibular joint TMJ is characterized by formation of a fibrous, bony, or fibro-osseous tissue between the mandibular condyle and glenoid fossa, which causes a limitation in movement of the jaw with an inability to open oral cavity. TMJ ankylosis usually is associated with disability of mastication, speech, swallowing, breathing, and nutrition. Moreover, it causes esthetic deformity because of disturbances of facial and mandibular growth. ${ }^{1}$

TMJ ankylosis is classified into four types according to severity and computed tomography observation ; TYPE I: Fibrous adhesion around the TMJ, inter-articular space reduction causing condylar displacement restriction, TYPE II: Bone bridge formation between the condyle and glenoid fossa, TYPE III: When a fracture of condylar process presents and the condyle (head and neck) suffers ankylosis to the glenoid fossa and TYPE IV: The whole TMJ architecture is replaced by an bone fusion of condyle, sigmoid notch and coronoid process to the glenoid cavity. ${ }^{2}$

It occurs most frequently in the first and second decades of life. It is commonly associated with trauma, general or local infectious disease, ankylosing spondylitis, rheumatoid arthritis, and previous TMJ surgery. ${ }^{3}$

Many surgical procedures currently used for treating TMJ ankylosis as joint reconstruction arthroplasty, interpositional arthroplasty, and gap arthroplasty are commonly used. The operative protocols for TMJ ankylosis may be one stage or multistage, depending on the severity and complexity of the disease. The basic principles are resection of the ankylotic lesion, coronoidectomy, early mobilization and aggressive postoperative physiotherapy., ${ }^{4,5}$

Piezosurgery device was originally developed for the atraumatic cutting of bone by ultrasonic vibrations as an alternative to the conventional mechanical and electrical instruments that are used in surgery regarding precision during the cut, reduced intraoperative blood loss, and lower incidences of postoperative nerve impairment, swelling, and hematoma?

The principle features of piezosurgery include the selective cutting of bone without damaging the adjacent soft tissue e.g. vessels, nerves or mucosa, providing a clear visibility in the operating field, and cutting with micron sensitivity without the generation of heat. Consequently, piezoelectric devices have demonstrated better clinical results when compared with traditional instruments, including precision during the cut, reduced intraoperative blood loss, and lower incidences of postoperative nerve impairment, swelling, and hematoma. ${ }^{8}$

The development of piezoelectric bone cutting has revolutionized maxillofacial surgery as ultrasonic vibrations, selective affinity for hard tissue, reduced heat generation and minimal damage to the soft tissue, blood vessels, and nerves in addition to the linear vibrations of the piezoelectric scalpel are practically ergonomic to the surgeon and do not affect dexterity when working in an anatomically delicate area. ${ }^{9}$

Since its first introduction, it has been widely used in various fields including orthopedics, neurosurgery, otorhinolaryngology, plastic surgery, dentistry and craniomaxillofacial surgery. However, few studies have evaluated its use for release of TMJ ankylosis. ${ }^{10-14}$

The aim of the current study was to evaluate surgical outcome of using piezoelectric device versus conventional drills in surgery of TMJ ankylosis.

\section{PATIENTS AND METHODS}

A prospective study included 18 joints in 10 patients suffered from bony ankylosis of the TMJ who were surgically managed by gap arthroplasty at oral and Maxillofacial Surgery department, Minia University Dental Hospital (MUDH) and Dar Al Shifa hospital of Egyptian Ministry of health.Patients selected according to the following inclusion criteria were considered: diagnosis with bilateral TMJ 
ankylosis affecting the articular surfaces; available clinical and radiological data; and postoperative follow up period of at least 6 months. The exclusion criteria were: patients with systemic disease; treatment with surgical approaches and techniques other than gap arthroplasty as interpositional grafts, reconstruction with costochondral graft and alloplastic reconstruction with hemi-joint/ total joint prostheses); and insufficient preoperative or postoperative data.

The preoperative assessment were performed by taking patient history, etiology of ankylosis, surgical data, mouth opening and computed tomography.

Patients were divided into 2 groups: Group A (removal of the ankylotic block by means of piezoelectric surgery), and Group B (management with high-speed drill and rotary bur).

All surgical procedures were performed by the first author with the same piezoelectric device and Electric micromotor with side cutting drills. under general anesthesia with nasotracheal intubation.

In all cases, Endural approach with temporal extension was adopted. After identification of the superficial temporal fascia, the dissection was carried out toward the periosteum of the zygomatic arch. Subsequently, a vertical incision of the joint capsule was performed with the fascia retracted anteriorly to protect the facial nerve.

The ankylotic block was exposed and removed either with a piezoelectric device or with a rotary burr to create a gap of approximately $1.5 \mathrm{~cm}$. Bone cutting was performed from the lateral to the medial side of the TMJ perpendicular to the cortical surface together with ipsilateral intraoral coronoidectomy. Bony spicules were smoothed, and hemostasis was achieved by diathermy. Figure 1

Care was taken toavoid the maxillary artery behind the medial aspect of the osseous mass. The wound was irrigated with saline solution, and a suction drain was inserted into the surgical wound and left in place until no more blood drained. Postoperative antibiotics were prescribed for all patients to reduce the possibility of infection ( Unictam 1500 vial ${ }^{\circledR}$; Sulbactam $500 \mathrm{mg}+$ Ampicillin $1000 \mathrm{mg}$; Medical Union Pharmaceuticals, Egypt) in addition to (Alpha chemotrypsin ampules ${ }^{\circledR}$; Amoun, Egypt) and Voltaren $75 \mathrm{mg}{ }^{\circledR}$ Diclophenac sodium ; Novartis pharma S.A.E. Egypt).

Patients were discharged after satisfactory clinical evaluation. Professional physiotherapy (jaw exercises of mouth opening), massage, and deep heat therapy were started 1 week after surgery. Regular long-term follow-up was performed at an outpatient clinic at 1 week, 1 month, 3 months, 6 months, and then annually after surgery. Postoperative computed tomography (CT) was performed . Figures 2 and 3

\section{Assessment parameters}

Evaluation and recording data were performed for all cases by the second author. Postoperative outcomes of TMJ surgery were investigated and compared based on the following parameters to address each device's advantages and disadvantages:

Postoperative outcomes of TMJ surgery were investigated and compared based on the following parameters to address each device's advantages and disadvantages:

Postoperative mouth interincisal opening MIO: a calibre was adopted to measure the degree of mouth opening (interincisal distance) during the regular follow-up; it was compared to preoper-

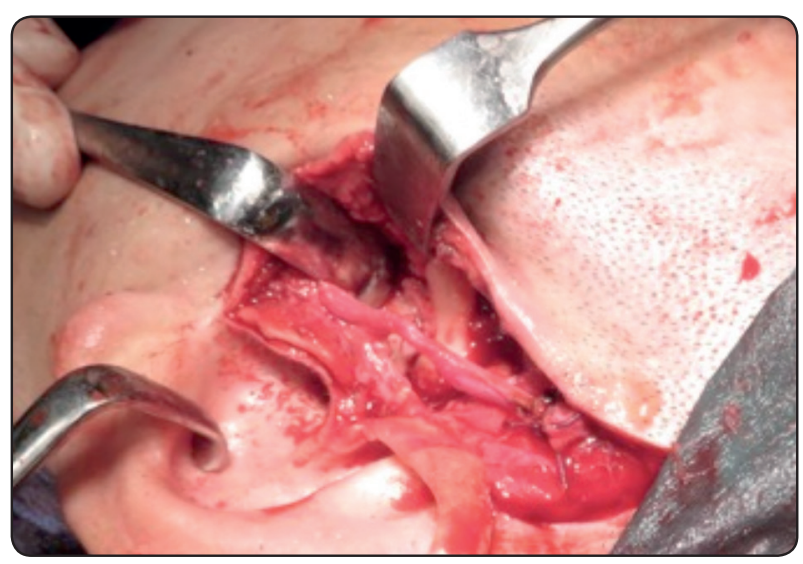

Fig. (1) Intraoperative image after release of ankylotic mass 


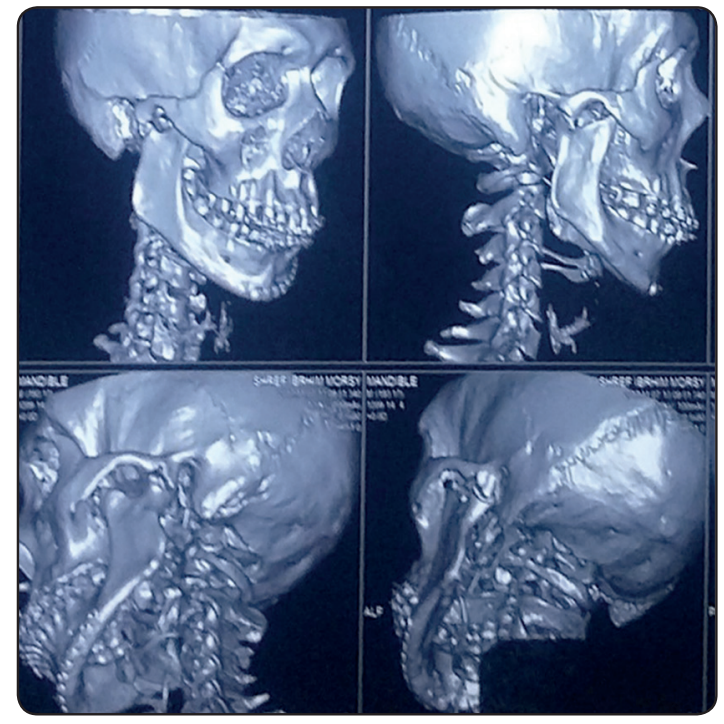

Fig. (2) Preoperative C.T. with 3D reconstruction showing bilateral TMJ ankylosis

.ative and intraoperative measurements Intraoperative bleeding: blood loss was measured from the same type of suction instrument during each procedure

Length of the operation time: duration of the procedure performed with the surgical drills was compared with the length of the procedure performed with the piezoelectric device

Surgical site infection: It was measured by ASEPSIS scoring method (Additional treatment, Serous discharge, Erythema, Purulent exudate, Separation of deep tissues, Isolation of bacteria and Stay as inpatient prolonged over fourteen days). ure 4 showing the scoring parameters. ${ }^{15}$

Surgical site swelling: it was calculated by difference between preoperative and postoperative summation of a 3 line measurements using 4 fixed points on surgical side of the face and finding the average. The fixed points used were A; the most posterior point on the tragus, $\mathrm{B}$; lateral canthus of the eye, $\mathrm{C}$; the most lateral point on the angle of the mouth,

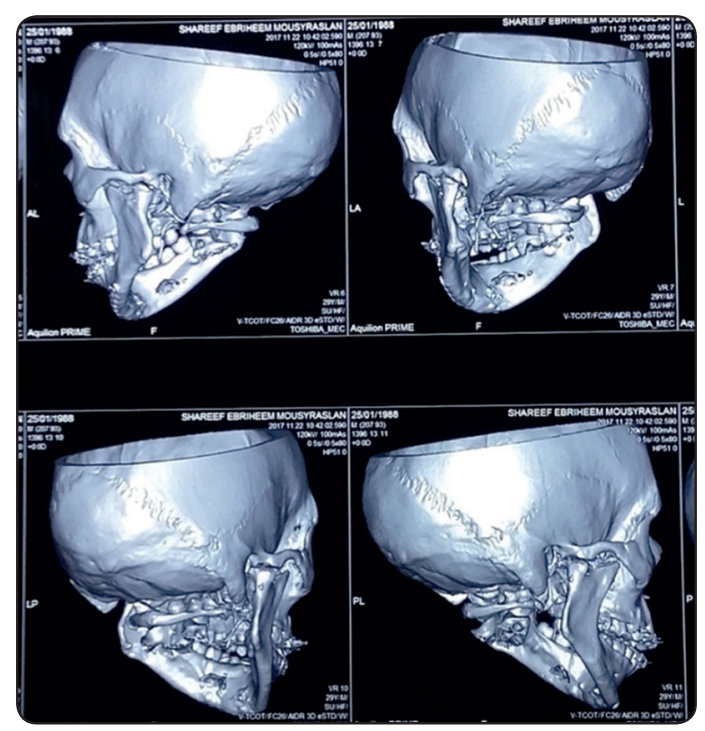

Fig. (3) Postoperative C.T. with 3D reconstruction

and $\mathrm{D}$; most inferior point on the angle of the mandible. The 3 lines were $\mathrm{AB}$, $\mathrm{AC}$ and $\mathrm{BD}$. The difference between the postoperative $3^{\text {rd }}$ day and preoperative . measurements was calculated

Postoperative pain: It was estimated subjectively by asking the patient to rate the nociceptive experience on a visual analog scale of 0 to 5 in the oper. ated site

Recorded data were analyzed using the statistical package for social sciences, version 20.0 (SPSS Inc., Chicago, Illinois, USA). Quantitative data were expressed as mean \pm standard deviation (SD). Independent-samples t-test of significance was used when comparing between two means. Paired sample t-test of significance was used when comparing between related sample. The confidence interval was set to $95 \%$ and the margin of error accepted was set to $5 \%$. So, the p-value was considered significant as the following; P-value $\leq 0.05$ was considered significant, P-value $\leq 0.001$ was considered as highly significant and $\mathrm{P}$-value $>0.05$ was considered insignificant.

\section{RESULTS}


Ten patients were selected in the current study; eight cases were bilateral and two cases were unilateral . Six patients were females and four were males. The ages ranged from 16 to 33 years, and the mean age was 24 years $(\mathrm{SD}=5.6)$. All cases were treated by gap arthroplasty. Group A consisted of 9 sides treated with piezoelectric device. Group B consisted of 9 side managed with traditional rotary burr. All cases subjected to follow up for 12 months.

The mean preoperative MIO was 8-25 mm (mean $13.92 \pm 5.33$ ). The intraoperative mouth opening was

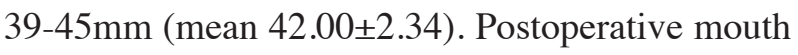
opening 38-42 (mean 39.58 \pm 1.38 ). at 1 st month mouth opening was $36-42 \mathrm{~mm}$ (mean $38.33 \pm 1.78$ ). at 6th month mouth opening was $29-38 \mathrm{~mm}$ $(34.83 \pm 2.79)$. at 1 year month mouth opening was $30-38(35.00 \pm 2.52)$. There was no relapse reported as considered mouth opening $<25 \mathrm{~mm}$ ). Table 1 .

As shown in table 2 The mean intraoperative blood loss, the mean length of the operation, 1 week Postoperative pain score, surgical infection score and the mean measure of swelling for group A and group B (conventional drills). Comparison between both groups revealed that ; there were no statistical difference between both groups in bleeding and surgical infection score. In addition to a statistically

TABLE (1): The extent of the difference over the periods through mouth opening in the study groups.

\begin{tabular}{|l|c|c|c|c|c|}
\hline MIO & Range & Mean \pm SD & Mean diff. & t-test & p-vaue \\
\hline Pre-operative & $8-25$ & $13.92 \pm 5.33$ & & & $<0.001^{* *}$ \\
\hline Intra operative & $39-45$ & $42.00 \pm 2.34$ & -28.08 & -19.603 & $<0.001^{* *}$ \\
\hline Post operative & $38-42$ & $39.58 \pm 1.38$ & -25.67 & -17.478 & $<0.001^{* *}$ \\
\hline 1st month & $36-42$ & $38.33 \pm 1.78$ & -24.42 & -15.563 & $<0.001^{* *}$ \\
\hline 3rd month & $35-40$ & $37.00 \pm 1.60$ & -23.08 & -14.623 & $<0.001^{* *}$ \\
\hline 6th month & $29-38$ & $34.83 \pm 2.79$ & -20.92 & -13.332 & $<0.001^{* *}$ \\
\hline 1st year & $30-38$ & $35.00 \pm 2.52$ & -21.08 & -12.544 & \\
\hline
\end{tabular}

This table shows statistically significant difference between preoperative and other periods through mouth opening in the study group.

TABLE (2): Comparison between group A and group B according to bleeding, swelling, pain score and surgical infection score.

\begin{tabular}{|c|c|c|c|c|}
\hline & Group A $(n=9)$ & Group B $(n=9)$ & t-test & p-value \\
\hline $\begin{array}{l}\text { Bleeding }(\mathbf{m l}) \\
\text { Mean } \pm \text { SD } \\
\text { Range }\end{array}$ & $\begin{array}{c}163.33 \pm 37.00 \\
120-210\end{array}$ & $\begin{array}{c}169.44 \pm 42.31 \\
115-230\end{array}$ & -0.326 & 0.749 \\
\hline $\begin{array}{l}\text { Swelling }(\mathbf{m m}) \\
\text { Mean } \pm \text { SD } \\
\text { Range } \\
\end{array}$ & $\begin{array}{c}10.22 \pm 2.22 \\
8-15\end{array}$ & $\begin{array}{c}12.44 \pm 2.65 \\
9-17 \\
\end{array}$ & -2.427 & $0.042 *$ \\
\hline $\begin{array}{l}\text { Pain score } \\
\text { Mean } \pm S D \\
\text { Range }\end{array}$ & $\begin{array}{c}2.44 \pm 0.88 \\
1-4\end{array}$ & $\begin{array}{c}3.44 \pm 0.88 \\
2-5\end{array}$ & -2.405 & $0.029 *$ \\
\hline $\begin{array}{l}\text { Surgical infection score } \\
\text { Mean } \pm \text { SD } \\
\text { Range }\end{array}$ & $\begin{array}{c}9.33 \pm 1.87 \\
8-14\end{array}$ & $\begin{array}{c}11.22 \pm 2.68 \\
8-16\end{array}$ & -1.733 & 0.102 \\
\hline $\begin{array}{l}\text { Time of surgery } \\
\text { Mean } \pm \text { SD } \\
\text { Range }\end{array}$ & $\begin{array}{c}107.78 \pm 12.02 \\
95-130\end{array}$ & $\begin{array}{c}74.44 \pm 9.82 \\
60-90\end{array}$ & 41.499 & $<0.001 * *$ \\
\hline
\end{tabular}




\begin{tabular}{|c|c|c|c|c|c|c|}
\hline \multirow[t]{2}{*}{ Wound characteristic } & \multicolumn{6}{|c|}{ Proportion of wound affected (\%) } \\
\hline & 0 & $<20$ & $20-39$ & $40-59$ & $60-79$ & $>80$ \\
\hline Serous exudate & 0 & 1 & 2 & 3 & 4 & 5 \\
\hline Erythema & 0 & 1 & 2 & 3 & 4 & 5 \\
\hline Purulent exudates & 0 & 2 & 4 & 6 & 8 & 10 \\
\hline Separation of deep tissues & 0 & 2 & 4 & 6 & 8 & 10 \\
\hline Criteria & \multicolumn{6}{|c|}{ Points } \\
\hline \multicolumn{7}{|l|}{ Additional treatment } \\
\hline Antibiotics & \multicolumn{6}{|c|}{10} \\
\hline $\begin{array}{l}\text { Drainage of pus under local } \\
\text { anesthesia }\end{array}$ & \multicolumn{6}{|l|}{5} \\
\hline $\begin{array}{l}\text { Debridement of wound } \\
\text { (general anesthesia) }\end{array}$ & \multicolumn{6}{|c|}{10} \\
\hline Serous discharge & \multicolumn{6}{|c|}{ Daily 0-5 } \\
\hline Erythema & \multicolumn{6}{|c|}{ Daily 0-5 } \\
\hline Purulent exudates & \multicolumn{6}{|c|}{ Daily 0-10 } \\
\hline Separation of deep tissues & \multicolumn{6}{|c|}{ Daily 0-10 } \\
\hline Isolation of bacteria & \multicolumn{6}{|c|}{10} \\
\hline $\begin{array}{l}\text { Stay as inpatient prolonged } \\
\text { over } 14 \text { days }\end{array}$ & \multicolumn{6}{|c|}{5} \\
\hline \multicolumn{7}{|l|}{ Category of infection } \\
\hline \multicolumn{7}{|l|}{ Total score } \\
\hline $0-10$ & \multicolumn{6}{|c|}{ Satisfactory healing } \\
\hline $\mid \mathrm{I}-20$ & \multicolumn{6}{|c|}{ Disturbance of healing } \\
\hline $21-30$ & \multicolumn{6}{|c|}{ Minor wound infection } \\
\hline $31-40$ & \multicolumn{6}{|c|}{ Moderate wound infection } \\
\hline$>40$ & \multicolumn{6}{|c|}{ Severe wound infection } \\
\hline
\end{tabular}

Fig. (4) ASEPSIS scoring method parameters

significant increase on group B compared to group A according to swelling and pain score $\mathrm{P}=0.042$, 0.029 and respectively. However time of surgery was increased significantly in group A. Table 2.

\section{DISCUSSION}

Various surgical procedures have been described for management of TMJ ankylosis including the gap (GA) or interpositional arthroplasty (IA), however there are a controversy in the best treatment method as no exclusive indications for might be unavailable because there are great overlaps between their coverage, especially when there is no significant loss of mandibular ramus height. ${ }^{16}$ In agreement a recent meta-analysis study included 8 studies for the comparison of reankylosis and the postoperative MIO between both procedures revealed that interpositional arthroplasty effectively improve MIO, but neither GA nor IA could completely prevent reankylosis for at least 1 year follow up considering that difference in MIO was only 1.96 $\mathrm{mm}$, that might not be a decisive factor influencing the surgeon in selection of the procedure. ${ }^{17}$

In accordance with the current study all patients were subjected to gap arthroplasty using piezoelectric device or conventional surgical drills with a significant improvement in MIO. The mean of MIO after 1year was 35.00 \pm 2.52 indicated no recurrence after 1 year follow up. No comparison between both devices regarding MIO was intended as 8 cases of total 10 cases were bilateral i.e both devices were used in the same case. These records were in accordance with many studies using the same procedure regardless the devices used. stable long-term postoperative MMO without reankylosis in the current study with regardless of the applied bone cutting technique, indicating gap arthroplasty is a predictable procedure for the treatment of TMJa. ${ }^{17,18}$

Long term muscle inactivity lead to anatomical changes and physiological weakness of the masticatory muscles which contribute in restriction of the mouth opening. Some authors outlined the evidence the immediate mobilization and aggressive physiotherapy, however others recommended physiotherapy after 7 days as immediate mobilization may lead to bleeding and creation of a hematoma that may delay the healing process. In the current study a professional physiotherapy are performed for all patients 1 week postoperative for the mentioned reason in addition to standardize pain, swelling and infection score assessment. ${ }^{19-21}$

Intraoperative bleeding measures revealed there was no statistical significant difference in blood loss between group treated by traditional drills compared to the group treated by piezoelectric device which is in disagreement with similar studies as they concluded that Piezoelectric bone 
removal for the release of ankylosis of the TMJ is associated with minimal bleeding and they referred that to the cavitation effect of the piezoelectric device and minimized damage to soft tissues and blood vessels. This contradiction may referred to the surgical approach and time of surgery as in the current study we used the same approach and steps in dissection with no injury to the maxillary nerve were reported in both groups. However other studies using conventional cutting method suggested that to protect the blood vessels and nerves, an extended incision, wide exposure of the ankylotic mass and aggressive retraction are often required . which may lead to a prolonged operation time postoperative swelling, pain, and scar. The measures in the current study were in the same patient between both sides considering that the significant difference in osteotomy time which was longer using piezoelectric device..$^{22,23}$

Postoperative swelling and Pain were more significant in the group treated with the conventional drills than in the piezoelectric group. these findings were in in accordance with the action of piezosurgery device as the cavitational energy generated by piezoelectric removes all cut debris and ensures a clean surgical field unlike other rotating conventional tools, it flushes out all the microparticles and cut debris and minimizes the undesirable seeding of cortical bone chips into the surrounding area. The damaged tissues and necrotic cut ends of the osteotomy site created by conventional drills coincide with the postoperative inflammatory edema substantially reduce local perfusion and lead to formation of hematoma, and postoperative inflammation. However reducing surgical trauma and inflammation by piezosurgery may reduce hypoxia at the local site and reduce those factors that ultimately lead to excessive formation of bone, however there were no recurrence in addition there are several factors contributing in the range of $\mathrm{MIO}$ as postoperative physiotherapy.
It was stated by Jia et al, the longer operation time may increase the risk of complications as ultrasonic surgery generally prolonged the operation time due to its lower efficacy during bone cutting, however, the average operation duration per joint showed no statistical significance in their study. They recorded the operation time from the skin incision to closure. Although the conventional method might be faster during bone cutting, it required more attention and time to archive adequate exposure and protect the soft tissue from potential injury. Moreover, they observed a significant positive association between blood loss and operation duration. ${ }^{24}$

In the current study the same approach and exposure by the same surgeon were performed in two groups and the time of operation represented the osteotomy time. The results indicated that although the longer operating time using piezoelectric device , there were no significant difference in infection score nor bleeding between both groups and significant reduced pain and swilling in piezoelectric device which proof a better postoperative outcome when using piezoelectric device. The postoperative care regimen was indicated in both groups may guarded against infection however postoperative results of pain and swilling are added value to the patient satisfaction.

In addition the selective bone cutting property of piezoelectric device when exploited in allowing the surgeon to perform a smaller approach and minimal retraction will add more benefits and advantage of this tool considering that the minimal approach will reduce the time of surgery. ${ }^{24,25}$

In conclusion; piezoelectric bone removal for the release of ankylosis of the TMJ reduced postoperative complications its main disadvantage is the increase in operating time . The piezosurgery allows surgeons to achieve better outcomes compared to a conventional surgery and its possible alternative due to the clinical benefits demonstrated. 


\section{REFERENCES}

1. Giannakopoulos, Helen E. et al. "Posttraumatic Temporomandibular Joint Disorders." Craniomaxillofacial Trauma \& Reconstruction 2009, (2)2 :91-101.

2. Eltohami YI, Abuaffan AH, Alsagh RA, et al. Temporomandibular Joint Ankylosis Pattern, Causes and Management among a Sample of Sudanese Children. Den Craniofac Res 2017, 2:1.

3. Felstead AM, Revington PJ . Surgical management of temporomandibular joint ankylosis in ankylosing spondylitis. Int J Rheumatol 2011: 1-5.

4. Baykul, Timucin et al. "Surgical Treatment of Posttraumatic Ankylosis of the TMJ with Different Pathogenic Mechanisms." European Journal of Dentistry 2012, (6)3: 318-323.

5. Bhardwaj, Yogesh, and Saurabh Arya. "Post-Ankylotic Temporomandibular Joint Reconstruction Using Autogenous/Alloplastic Materials: Our Protocol and Treatment Outcomes in 22 Patients." Craniomaxillofacial Trauma \& Reconstruction 9.4 (2016): 284-293.

6. Katsnelson A, Markiewicz MR, Keith DA, Dodson TB. Operative management of temporomandibular joint ankylosis: a systematic review and meta-analysis. J Oral Maxillofac Surg. 2012; 70:531.

7. Firoz Babu P, Polepalle T, Loya M, Mani Deepthi CH and Nayyar AS. Piezosurgery: A Boon to Dentistry. J Dent App. 2016; 3(4): 365-369.

8. Yaman Z, Suer BT. Piezoelectric surgery in oral and maxillofacial surgery. Annals of Oral \& Maxillofacial Surgery 2013 01;1(1):5.

9. Gleizal, A., Bera, J. C., Lavandier, B. \& Beziat, J. L. Piezoelectric osteotomy: a new technique for bone surgery - advantages in craniofacial surgery. Child's Nervous System. 2007,23;509-13.

10. Kramer, F. J. et al. Piezoelectric osteotomies in craniofacial procedures: a series of 15 pediatric patients. Journal of Neurosurgery: Pediatrics. 2006,104, 68-71.

11. Meller, C. \& Havas, T. E. Piezoelectric technology in otolaryngology, and head and neck surgery: a review. The Journal of Laryngology \& Otology. 2017;131, S12-S18.

12. Pavlíková, G. et al. Piezosurgery in oral and maxillofacial surgery. International Journal of Oral and Maxillofacial Surgery.2011, 40, 451-7.

13. Martini, M., Röhrig, A., Reich, R. H. \& Messing-Jünger, M. Comparison between piezosurgery and conventional osteotomy in cranioplasty with fronto-orbital advancement. Journal of Cranio-Maxillofacial Surgery. 2017,45, 395-400.
14. Troedhan, A. Piezotome rhinoplasty reduces postsurgical morbidity and enhances patient satisfaction: a multidisciplinary clinical study. Journal of Oral and Maxillofacial Surgery. 2016,74, 1659.-1659.

15. Copanitsanou P, Kechagias VA, Grivas TB, Wilson P. Use of ASEPSIS scoring method for the assessment of surgical wound infections in a Greek orthopaedic department. Int J Orthop Trauma Nurs. 2018 ;30:3-7.

16. Danda AK, S R, Chinnaswami R. Comparison of gap arthroplasty with and without a temporalis muscle flap for the treatment of ankylosis. J Oral Maxillofac Surg. 2009; 67:1425-1431.

17. Ma J, Liang L, Jiang H, Gu B. Gap Arthroplasty versus Interpositional Arthroplasty for Temporomandibular Joint Ankylosis: A Meta-Analysis. PLoS One. 2015;10(5).

18. Jain G, Kumar S, Rana AS, Bansal V, Sharma P, Vikram A.Temporomandibular joint ankylosis: a review of 44 cases. Oral Maxillofac Surg. 2008 ;12(2):61-6.

19. Babu L, Jain MK, Ramesh C, Vinayaka N: Is aggressive gap arthroplasty essential in the management of temporomandibular joint ankylosis? da prospective clinical study of 15 cases. Br J Oral Maxillofac Surg 2013, 51:473-478.

20. Su-Gwan K: Treatment of temporomandibular joint ankylosis with temporalis muscle and fascia flap. Int J Oral Maxillofac Surg , 2001,30: 189-193.

21. Ying QV, Bacic J, Abramowicz S, Sonis A: Cross sectional: normal maximal incisal opening and associations with physical variables in children. Pediatr Dent, 2013, 35: 61-66.

22. Spinelli G, Valente D, Mannelli G, Raffaini M, Arcuri F. Surgical management of ankyloses of the temporomandibular joint by a piezoelectric device. Journal of CranioMaxillo-Facial Surgery $2017,45: 441-448$.

23. Jose A, Nagori SA, Virkhare A, Bhatt K, Bhutia O, Roychoudhury A. Piezoelectric osteoarthrectomy for management of ankylosis of the Temporomandibular joint. Br J Oral Maxillofac Surg. 2014 ;52(7):624-8.

24. Jia T, Wang L, Chen Y, Zhao R, Zhu L, Xing L, Rao N, Zhang J, Zhang Q, August M, Han Y, Zhang H. Ultrasonic versus conventional gap arthroplasty for the release of ankylosis of temporomandibular joint: a prospective cohort study. Sci Rep. 2019; 23;9(1):385.

25. Gonzalez-Lagunas, J. Is the piezoelectric device the new standard for facial osteotomies? Journal of Stomatology, Oral and Maxillofacial Surgery. 2017,118; 255-258. 